\title{
Chinese health care system and clinical epidemiology
}

This article was published in the following Dove Press journal:

Clinical Epidemiology

16 March 2017

Number of times this article has been viewed

\author{
Yuelian Sun' \\ Hans Gregersen² \\ Wei Yuan ${ }^{3}$ \\ 'Department of Clinical Epidemiology, \\ Aarhus University Hospital, Aarhus, \\ Denmark; ' ${ }^{\mathrm{G} I O M E}$, Department of \\ Surgery, Chinese University of Hong \\ Kong, Hong Kong, ${ }^{3}$ Key Laboratory of \\ Reproduction Regulation of NPFPC, \\ SIPPR, IRD, Fudan University, Shanghai, \\ People's Republic of China
}

Correspondence: Yuelian Sun Department of Clinical Epidemiology, Olof Palmes Allé 43-45, DK-8200

Aarhus N, Denmark

Tel +4587I68254

Email ys@clin.au.dk
Abstract: China has gone through a comprehensive health care insurance reform since 2003 and achieved universal health insurance coverage in 2011. The new health care insurance system provides China with a huge opportunity for the development of health care and medical research when its rich medical resources are fully unfolded. In this study, we review the Chinese health care system and its implication for medical research, especially within clinical epidemiology. First, we briefly review the population register system, the distribution of the urban and rural population in China, and the development of the Chinese health care system after 1949. In the following sections, we describe the current Chinese health care delivery system and the current health insurance system. We then focus on the construction of the Chinese health information system as well as several existing registers and research projects on health data. Finally, we discuss the opportunities and challenges of the health care system in regard to clinical epidemiology research. China now has three main insurance schemes. The Urban Employee Basic Medical Insurance (UEBMI) covers urban employees and retired employees. The Urban Residence Basic Medical Insurance (URBMI) covers urban residents, including children, students, elderly people without previous employment, and unemployed people. The New Rural Cooperative Medical Scheme (NRCMS) covers rural residents. The Chinese Government has made efforts to build up health information data, including electronic medical records. The establishment of universal health care insurance with linkage to medical records will provide potentially huge research opportunities in the future. However, constructing a complete register system at a nationwide level is challenging. In the future, China will demand increased capacity of researchers and data managers, in particular within clinical epidemiology, to explore the rich resources.

Keywords: China, health care, insurance, registry, clinical epidemiology

\section{Background}

China is going through a comprehensive health care insurance reform. ${ }^{1,2}$ Within a decade after the implementation of the Chinese health insurance reform in 2003 for residents in rural areas, health insurance coverage reached $95 \%$ of the population in $2011 .^{2}$ The new health care insurance system provides China with a huge opportunity for the development of health care and medical research when the rich medical resources are fully unfolded.

In this paper, we aim to review the Chinese health care system and its implication for medical research, especially within clinical epidemiology. To better understand the issue, we first briefly review the population register system, the distribution of urban and rural populations, and the development of the Chinese health care system after 1949. In the following sections, we describe the current Chinese health care delivery system and the current health insurance system. We then focus on the construction 
of the Chinese health information system as well as several existing registers and research projects on health data. Finally, we discuss the opportunities and challenges of the health care system in regard to clinical epidemiology research.

\section{The population register system and distribution of urban and rural populations}

China has the largest population in the world, totaling 1.37 billion people in $2014 .^{3}$ The majority of the population used to live in rural areas, mainly working with agriculture. When China was established in $1949,89.4 \%$ of its population lived in rural areas. This proportion has been decreasing with the economic development and urban expansion. In 2010, China's population was distributed equally between urban and rural areas, but in 2014, the proportion of registered rural residents had decreased to $45.2 \% .^{3}$

Chinese citizens in the mainland are registered in the household register system, called "Hukou" in Chinese. ${ }^{4,5}$ There are two types of household register, the urban (nonagricultural in Chinese to be precise) household register and the rural (agricultural) household register. The system is used for administration of the population and at the same time determines eligibility for welfare benefits, such as housing, employment, education, and health care. ${ }^{4,5}$ People in urban areas usually have better living conditions due to more stable job opportunities and access to more and better education and health care. People who are employed either in government institutions, factories, or other institutions in urban areas are provided with several types of insurance, including unemployment insurance, pension, and health care. People covered by the rural household register are supposed to live from agriculture and jobs in township enterprises. Most rural residents had no basic pension and health care insurance until the initiation of the social insurance reform in recent years.

Although the household register system to some extent restricts the mobility of the population, millions of people in the rural areas move to other places, especially to big cities for work. They constitute the major part of the "migrant population" or "floating population", which refer to those who live for 6 months or longer in a place different from the place they were registered (not including those still in the same municipality or prefecture city). ${ }^{3}$ In 2014 , the migrant population reached 253 million. ${ }^{3}$ Thus, one out of six Chinese fall into the category of the migrant population. Health care to this group is a concern. Most of the migrant population from rural areas converge in private sectors or engage in individual business, working in manufacturing, and other labor intensive sectors, such as wholesale and retail trade, hotels and catering, and social services. ${ }^{6}$ The migrant population includes vulnerable groups, such as women and children. The number of migrant women of childbearing age has increased and reached 63 million in 2012, accounting for $25 \%$ of all married women of childbearing age across the country. ${ }^{7}$ The National Health and Family Planning Commission has started a project to reinforce equal health care for the migrant population.

\section{Development of the Chinese health care system}

The evolvement of the Chinese health care system was divided into four phases according to a recent report based on the characteristics of the health care system in the four periods. ${ }^{1}$ Especially the dramatic change of the health care system for residents in rural areas is helpful for understanding the development of the Chinese health care system. We cite the development here in a revised form.

\section{Phase I (1949-1983)}

Despite limited health resources, China achieved improved health status of the population in the first 30 years after its establishment in 1949. A distinctive accomplishment of this phase was the establishment of the Rural Cooperative Medical System (RCMS) in rural areas, in which community health workers (the Chinese nickname is "barefoot doctors") provided basic public and personal health services for residents in the villages. Officers in the government and workers in enterprises in urban areas benefited from social medicine and the labor medicine system, where the government or enterprises paid almost all medical care expenses. Health care services were nearly free for individuals.

\section{Phase 2 (1984-2002)}

The well-established cooperative medical system for the rural areas collapsed within a short time period after the economic reforms in China in the late 1970s, leaving the vast majority of the rural population without health care. In 1999, only $7 \%$ of the 900 million rural residents had some kind of health insurance coverage. ${ }^{1}$ People in urban areas were also affected as many factories did not survive the economic reforms. Thus, the proportion of urban residents covered by health insurance decreased to $49 \%$ in 1999 , whereas social medicine and the labor medicine system covered about two-thirds of the urban population in 1993. ${ }^{1,8}$ However, free medical care for urban employees was a burden to the government and enterprises, which demanded reforms. A pilot reform was introduced in 1992, allowing individual contribution to medical care expenses. In 1998, the Chinese Government issued the Urban Employee Basic Medical Insurance (UEBMI), in which the employers pay for part of the insurance premium for employees. 


\section{Phase 3 (2003-2008)}

In 2003, the government took steps to reform the health care system by initiating a New Rural Cooperative Medical Scheme (NRCMS) for the rural population. ${ }^{9}$ In 2007, the government introduced the Urban Residents Basic Medical Insurance (URBMI) for urban nonemployed citizens like children, students, elderly people without previous employment, and unemployed people, who were not covered by the UEBMI. ${ }^{10}$ Initially, the NRCMS and the URBMI reimbursed only inpatient expenditures. ${ }^{11}$

\section{Phase 4 (2009-now)}

A more comprehensive and historic health reform was introduced in 2009, when the Chinese Government increased the financing of the health care system reform focusing on five areas: service delivery, essential medicines, public health, insurance, and public hospital reforms. ${ }^{12,13}$ The government recommitted itself to the ethical principle of social solidarity, and the principles of "equalization of access to public services" for all. ${ }^{12}$ During 2009 and 2010, the central government invested 42.2 billion yuan in health care facilities throughout the country, which was more than the sum of all the investments the government made in the 30 years since China's economic reform in the late 1970s. ${ }^{12}$ In 2011, the government announced its intention to increase investments to 1.13 trillion yuan with a 3 -year plan. ${ }^{13}$ Reimbursements for outpatient care in the NRCMS and the URBMI were introduced in 2009, and individual copayments for outpatient and inpatient care were reduced significantly. ${ }^{9}$ As a result of the health care reform, the Chinese people's health status improved, especially for residents in rural areas. For example, the maternal mortality dropped from 80 in 1991 to 25 in 2012 per 100,000 livebirths and the neonatal mortality dropped from 33 in 1991 to 7 in 2012 per 1000 livebirths. ${ }^{14}$ The difference in urban and rural maternal mortality narrowed from $1: 2$ in 2005 to $1: 1$ in $2010 .^{12}$

\section{The Chinese health care delivering system}

The present health care delivering system in China is generally organized according to government administration (Figure 1), which includes central, provincial, prefectural

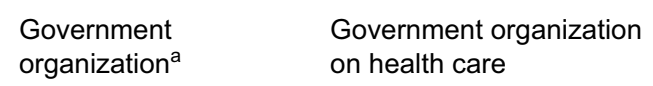

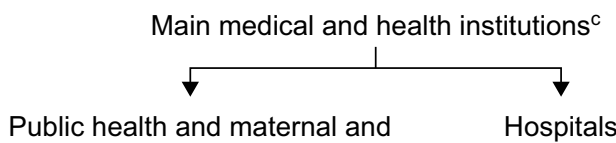

child health institutions
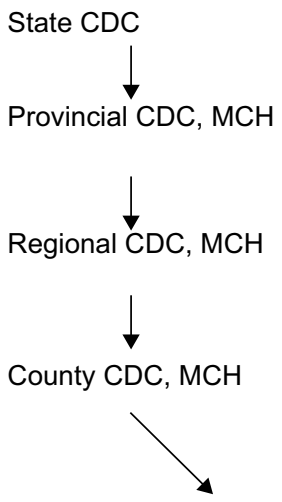

Township/urban subdistrict health centers

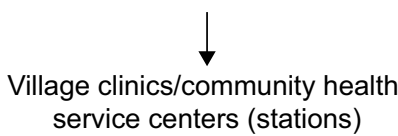

Village residents'

committee/community residents' committee

Figure I Chinese health care system.

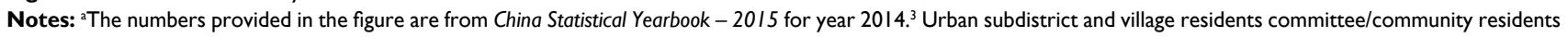
committee are not government organizations. ${ }^{b} \mathrm{~A}$ total of 31 provincial governments including four municipalities, five autonomous regions, and 22 provinces (Taiwan, Hong Kong, and Macau are not included). ${ }^{c}$ The following types of health institutions are not listed: health inspection institutions, specialized disease prevention and treatment, health education institutions, first aid centers, blood gathering and supplying institutions, health supervision and inspection agencies, sanatoriums, clinical laboratory centers, medical scientific research institutions, on-job training institutions, medical examination centers.

Abbreviations: CDC, Centers for Disease Control and Prevention; HFPC, Health and Family Planning Commission; MCH, Maternal and Child Health Institutions. 
(regional), county, and township levels. ${ }^{10}$ Each township (in rural areas) or subdistrict (in urban areas) is in charge of several villages or residents communities. ${ }^{10}$ Each government unit at the county level or higher has a functional health bureau under dual control of the corresponding government and the health bureau of a higher administrative level. ${ }^{15}$ Thus, the Chinese health care delivering system comprises several vertical segments. ${ }^{10,15}$ Interested readers are referred to a report by Fang presenting the health system in a different way. ${ }^{16}$ Health care service provision in China is broadly divided into three segments. ${ }^{10}$

\section{Specialized public health services}

These services are carried out by Centers of Disease Control and Prevention (CDC) and health care agencies for women and children. In China, people use the term "specialized public health services" to refer to services provided by public institutions rather than primary care providers. The state CDC oversees the public health management in China. Governments at provincial, prefectural, and county levels usually have a CDC and also a health care agency for women and children. In 2014, there were 3,490 CDCs and 3,098 health care agencies for women and children in China. ${ }^{3}$

\section{Primary public and clinical health care}

The primary health care services are carried out by subdistrict health centers, community health service centers (stations) in the urban areas, township health service centers, village clinics in the rural areas, and outpatient departments in both areas. The total number of primary health care institutions reached 917,335 in 2014, including 595 subdistrict health centers, 34,238 community health service centers (stations), 36,902 township health service centers, 645,470 village clinics, and 200,130 outpatient departments. ${ }^{3}$

\section{Curative health care (secondary and tertiary)}

Curative health care services are carried out by hospitals. They are categorized into public (government, 66\%) and nonpublic, according to ownership. Hospitals in China are accredited as levels 1-3. Hospitals of level one in general correspond to hospitals at township level for primary public and clinical health care introduced in Primary public and clinical health care section. Hospitals of level two correspond to hospitals at the county and prefectural levels providing comprehensive health service with coverage for certain regions. Hospitals of level three are more likely at the provincial level providing comprehensive or advanced health service with coverage for province or even the whole nation. Hospitals in each level are ranked $\mathrm{A}$ and $\mathrm{B}$ on the basis of the functions, size, technical skills, equipment, and quality of service. A hospital ranked as $\mathrm{A}$ in level three is the best. In 2014, China had 16,524 general hospitals, 3,115 hospitals specialized in traditional Chinese medicine, and 5,478 specialized hospitals. ${ }^{3}$ Selling prescription drugs has been a major source of revenue for hospitals, which provided hospitals and doctors with strong incentives to demand more drugs and more expensive drugs. In 2015, the Chinese Government financed a pilot program to eliminate markup of prescription drug prices, which has shown effective in reducing total medical expenditures. ${ }^{16}$

Village clinics, township health centers, and hospitals at the county level constitute the basic rural health care delivery system. Although the number of primary health care institutions is high, these institutions only possess basic health care equipment. Health care needs that cannot be managed by primary health care institutions are referred to hospitals and other specialized health institutions at the county level. This is called the village-town-county three-tier referral system for the rural area. The three-tier system played an important role in providing health care to the rural residents in the first 30 years after China's establishment in 1949. After the economic reform, the system did not function well due to the collapse of the RCMS. After the expanded health care reform in 2009, the government has improved the capacity of basic primary health care institutions by building new or rebuilding existing township health care centers and village clinics in the rural areas and community health care centers and stations in the urban areas. The government financed equipment and facilities, as well as personnel training. ${ }^{12}$ Now every residents community in all of China's cities has one community health service center. ${ }^{12}$

\section{The current Chinese health insurance system}

The insurance schemes, the UEBMI and the URBMI for employees and residents in the urban areas and the NRCMS for residents in the rural areas, now cover all Chinese citizens. However, the three insurance programs differ in how they are financed and operated. ${ }^{10}$ Table 1 presents the characteristics of the three health insurance schemes. In addition to the three basic health care insurances, insurances for critical illness, medical assistance (MA), and emergency disease assistance exist. Together they form a complete insurance system that protects Chinese citizens from expenses related to medical conditions. In the literature, the reform of the Chinese Health Insurance System has already been introduced by, for example, the World Health Organization's and the World Bank's reports. ${ }^{10,17,18}$ We briefly describe the Chinese health insurance system here. 
Table I Summary of China's three health insurance programs

\begin{tabular}{|c|c|c|c|}
\hline Contents & UEBMI & URBMI & NRCMS \\
\hline Target population & Urban employees & $\begin{array}{l}\text { Urban residents, eg, children, } \\
\text { students, elderly people without } \\
\text { previous employment }\end{array}$ & Rural residents \\
\hline Unit of enrollment $\mathrm{e}^{\mathrm{e}}$ & Individuals & Individuals & Households \\
\hline Type of enrollment ${ }^{e}$ & Compulsory & Voluntary & Voluntary \\
\hline Source of premium & Employer and individual & Government and individual & Government and individual \\
\hline Benefits package & Inpatient and outpatient care & $\begin{array}{l}\text { Inpatient and outpatient care } \\
\text { and critical illness insurance }\end{array}$ & $\begin{array}{l}\text { Inpatient and outpatient care and } \\
\text { critical illness insurance }\end{array}$ \\
\hline Management level of pooling fund ${ }^{e}$ & Prefecture/municipality & Prefecture/municipality & County \\
\hline Number of pools of risk fund (approx) ${ }^{e}$ & 330 & 330 & 2600 \\
\hline Overseeing government & MOHRSS & MOHRSS & NHFP \\
\hline Year of pilot ${ }^{\mathrm{e}}$ & $1994^{\mathrm{a}}$ & 2007 & 2003 \\
\hline Year of formal launch & 1998 & 2009 & 2006 \\
\hline \multicolumn{4}{|l|}{ Facts in 2014} \\
\hline Enrollment rate, \% & $>95$ & $>95$ & 98.9 \\
\hline Number of enrollees, million & 283 & 315 & 736 \\
\hline Proportion of population, $\mathrm{b} \%$ & 21 & 23 & 54 \\
\hline Premium per capita (Yuan) & $1962^{c}$ & 410 & 411 \\
\hline \multicolumn{4}{|l|}{ Benefit coverage } \\
\hline Reimbursement rate for inpatient care, $\%$ & 80 & 70 & 75 \\
\hline Reimbursement rate for outpatient care, \% & $50,70,80^{d}$ & 50 & 50 \\
\hline Number of reimbursable serious illnesses & - & 22 & 22 \\
\hline
\end{tabular}

Notes: aefore 1994, employees were insured through the government insurance system and the labor insurance system. In 1994 , both of them were converted into the

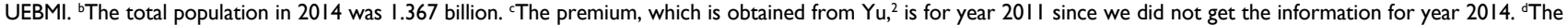
reimbursement rates differ for different insured populations in different provinces. The numbers are reimbursement rates for current employees, retired employees under 70 years of age, and retired employees of 70 years of age and older in Beijing after payment for certain nonrefundable amounts. ${ }^{69}$ eAdapted from Liang, Lilin; Langenbrunner, John C. The Long March to Universal Coverage : Lessons from China. UNICO Study Series; No. 9. World Bank, Washington DC. 2013. () World Bank. https://openknowledge. worldbank.org/handle/I0986/I3303 License: CC BY 3.0 IGO. Creative Commons license and disclaimer available from: http://creativecommons.org/licenses/by/4.0/legalcode. ${ }^{10}$ Abbreviations: MOHRSS, Ministry of Human Resource and Social Security; NHFP, National Health and Family Planning Commission; NRCMS, New Rural Cooperative Medical Scheme; UEBMI, Urban Employee Basic Medical Insurance; URBMI, Urban Residence Basic Medical Insurance.

\section{Urban Employee Basic Medical Insurance (UEBMI)}

The UEBMI was initiated in 1994 and formally launched in 1998 to replace the previous insurance system for urban employees and retired employees. ${ }^{10}$ In this new insurance system, both employers and employees contribute to the annual premium equal to $8 \%$ of the payroll. Employers pay $6 \%$ as tax and employees pay $2 \%$, while retired employees who already paid for the minimum required number of years (25 years for males and 20 years for females) do not have to contribute the premium. ${ }^{10,11}$ It is a mandatory program. Seventy percent of the employer contribution goes to social pooled funds, which are used for inpatient reimbursements and critical outpatient reimbursements. The rest of premium goes to individual medical savings accounts, which can be directly used for outpatient care and purchase of registered medicine.

\section{Urban Residence Basic Medical Insurance (URBMI)}

The URBMI was initiated in 2007 and formally launched in 2009 to cover urban residents who were not covered by the UEBMI. ${ }^{10}$ It is a voluntary program. The annual premium is largely paid by the government, while individuals pay for a small proportion. The premium has increased with time. For example, the premium increased from 131 yuan in 2008 to 570 yuan in $2016 .{ }^{19,20}$ Of the premium in 2016,420 yuan is paid by the government and 150 yuan is paid by the individual. ${ }^{20}$ At the beginning, the insurance program covered inpatient care only. Outpatient reimbursements were included in 2009. The proportion of reimbursements in the URBMI has increased with time and reached $70 \%$ for inpatients and $50 \%$ for outpatients in 2014. ${ }^{21}$ Both the UEBMI and the URBMI funds are pooled at the prefectural/municipal level and managed by the Ministry of Human Resource and Social Security.

\section{New Rural Cooperative Medical Scheme (NRCMS)}

The NRCMS was initiated in 2003 and formally launched in 2006 to cover rural residents. It is a voluntary program. Similar to the URBMI, the annual premium is largely paid by the government, while individuals pay a small proportion. The premium has increased with time. For example, the premium increased from 30 yuan in 2003 to 411 yuan in 2014. ${ }^{10}$ At the beginning, the insurance program covered only inpatient care. In 2009, all premiums were pooled at the county level and then divided into outpatient funds and hospitalization (inpatient) funds. The first one accounts for $\sim 30 \%$ of total funds while the second one represents $67 \%$ of the total. The remaining $3 \%$ is allocated for a risk fund. ${ }^{22}$ 
The compensation ratio for inpatient care has increased with time and reached $75 \%$ in $2010.9^{9,21}$ The NRCMS is managed by the National Health and Family Planning Commission. By the end of 2014, 736 million rural residents had joined the NRCMS, corresponding to $98.9 \%$ of the rural population..$^{3,11}$

\section{Critical illness insurance}

Critical illness insurance is an extension of the basic medical care system that gives further security to urban and rural residents if large medical expenses are incurred from their critical illness. ${ }^{23,24}$ Two documents on implementing and comprehensively implementing critical illness insurance for urban and rural residents were issued in 2012 and $2015 .^{23}$ The 2015 document states that the critical illness insurance should cover all participants in the URBMI and the NRCMS, no extra premium should be paid for the insurance, and the insurance reimbursement proportion for medical expenditures should reach $50 \%$ by the end $2015 .{ }^{23}$ China's critical illness insurance program helped 1.15 million patients in $2014 .^{25}$

\section{The MA program}

The target of MA is people in the existing social security network, such as low income households, who get the minimum living allowance from the government. ${ }^{10}$ The MA program was introduced by paying premiums for the target residents in the NRCMS in $2003,{ }^{10}$ and covered the target residents in URBMI in 2007. MA covers part of the remainder of a medical bill that is not reimbursed by the NRCMS and the URBMI. The MA program is managed by the Ministry of Civil Affairs and pooled at the county level by the Bureau of Civil Affairs. In 2011, financial assistance from MA was received by $1.8 \%$ of the NRCMS enrollees and 3\% of the URBMI enrollees. ${ }^{10}$

\section{Emergency disease assistance}

An emergency disease assistance program was issued by the Chinese Government (the State Council of China) to help individuals with an unknown identity who have emergency diseases, or individuals who cannot afford to pay for emergency situations. ${ }^{26}$ The assistance fund is mainly financed by local government and donations. Medical health care institutions involving specific emergency disease assistance can apply for reimbursements.

\section{Integrating the basic medical insurance systems for urban and rural residents}

In January 2016, the State Council issued a document on Integrating the Basic Medical Insurance Systems for Urban and Rural Residents to establish a unified basic medical insurance system for urban and rural residents regarding insurance premium, breadth (proportion of the population covered), depth (proportion of the health costs covered), and scope (type of health services covered). ${ }^{2,27}$ The administration of the two insurance systems will also be unified. The premium of the UEBMI is much higher than the premium of the URBMI and the NRCMS leading to substantial benefit variations across insurance programs (Table 1). ${ }^{19}$ However, the gap has decreased due to the increase in premiums and in the reimbursement proportion of the URBMI and the NRCMS in recent years, and the increase of the number of the disease in the critical illness insurance (Table 1). The number of enrollees in the URBMI and the NRCMS increased rapidly within a few years after initiation of the insurance programs, which largely contributes to universal health insurance coverage in China (Table 1).

\section{Health information system and selected health registers and projects}

Reforming the Chinese health care system is an extremely complicated process. Health information technology (HIT) has been recognized as one of eight important support systems in achieving success of the reform. ${ }^{12,18,28}$

\section{Construction of electronical individual health care records}

In 2009, the Chinese Ministry of Health proposed a plan to build a model gradually for regional integrated and coordinated health care services based on digitized health records of residents. ${ }^{12}$ National standards for a number of health databanks, for example, women's and children's health maintenance information, and a hospital information platform have been developed. ${ }^{12}$ "Regulation on medical records management in medical institutions" requires that all medical institutions at any level must establish the medical record management system using a unique medical record identification (ID) number. ${ }^{29}$ The medical record ID number should also be linked with the ID number of a patient. ${ }^{29}$ In 2011, 9.5 billion yuan was allocated to promote HIT in hospitals, including the establishment of electronic medical records, which refer to patient records for clinical purposes, or electronic health records, which refer to longitudinal health data on the population across care settings. ${ }^{28}$ The Ministry of Health established a standards bureau office and a series of standards regarding architecture, regulations, and function profiles of electronic medical records were issued. ${ }^{28}$ Nearly every health care provider has set up its own electronic health records system. ${ }^{16}$ Within hospitals, electronic health records are also linked to the health insurance systems for payment of claims with unique patient ID number. However, the 
electronic health records systems vary significantly between hospitals and are usually not integrated or interoperable. Patients often have to bring with them a printed health record if they would like to see doctors in different hospitals. ${ }^{16}$ In 2011, the Ministry of Health began to develop the "Resident Health Card" project. ${ }^{12}$ The card links the individual's electronic health and medical records and will provide the key link for cross-institutional, transregional data sharing.

\section{Data from the medical insurance scheme}

Data from basic medical insurance schemes are becoming rich resources for research. A few studies have been conducted based on data from the basic medical insurance schemes. For example, the Beijing UEBMI scheme included 13 million residents in 2012. ${ }^{30}$ Of these, 5 million used some form of health care service or made visits to clinics. Associated clinical records are available in the database. ${ }^{30}$ The Nanjing Medical Insurance Information System was established in 2000 and records all medical insurance data, including the Nanjing UEBMI population. ${ }^{31}$ Information on patient hospital visits is submitted to the system automatically including diagnosis, medicine prescribed, and health care costs. ${ }^{31,32}$

\section{Existing health registers and research projects}

With the development of electronic medical records and health insurance databases, existing health registers and research projects may potentially be expanded. Some registers and projects are reviewed below.

\section{Surveillance for communicable diseases}

China has conducted surveillance for communicable diseases via the disease surveillance points (DSPs) system in order to control these diseases since $1950 .{ }^{33}$ The DSP system covers 161 counties and districts in 31 provinces and is used primarily for surveillance of communicable diseases. ${ }^{34}$ In January 2004, a real-time, case-specific, and web-based disease surveillance system was set up. ${ }^{33,35,36}$ The system monitors 37 communicable diseases and included death reports from April 2004. The state CDC developed a nationwide webbased automated system for outbreak detection and rapid response to communicable diseases. ${ }^{37}$

\section{Cancer registries}

The oldest local cancer registries in China were established in Henan in 1959, in Shanghai in 1964, and in Jiangsu in $1972 .{ }^{38,39}$ In 2002, there were 48 cancer registries in China covering $\sim 73$ million citizens ( $5.7 \%$ of the population). The National Central Cancer Registry of China (NCCR) was established in the same year to collect and evaluate cancer data reported from local cancer registries. ${ }^{40}$ In 2008, the Ministry of Health launched a national program to support cancer registries. The number of population-based registries at county level or above increased to 308 covering of 300 million people (22\%) in $2014 .{ }^{40}$ However, the quality of the local cancer registries varies. ${ }^{39-41}$

\section{Epidemiological research projects on cancer and other chronic diseases}

The Shanghai cohort study recruited 18,244 men aged 45-64 years in Shanghai during 1986-1989 to study risk factors for cancer and other chronic diseases, including cardiovascular disease and diabetes. ${ }^{42}$ More than 35 peer-reviewed articles have been published based on the cohort. ${ }^{43-45}$ Another two large studies, the Shanghai Women's Health Study (SWHS) and the Shanghai Men's Health Study (SMHS) were launched in 1996 and 2002, aiming to investigate the etiology of cancer and other chronic diseases. ${ }^{46-49}$ A total of 74,741 women aged 40-70 years were recruited for the SWHS in 1996-2000 46,47 and 61,480 men aged 40-74 years were recruited for the SMHS in 2002-2006. Both studies are prospective cohort studies with information on diet, reproductive history, hormone use, physical activity, weight history, and body measurements. Biological samples, including urine, blood, and buccal cells, were collected. The cohorts have been followed up using both medical record linkage and active follow-ups.

In 2004, the Chronic Disease and Risk Factor Surveillance was set up in China via the DSP system to study hypertension, diabetes, stroke, obesity, and other conditions. ${ }^{34}$ Participants were chosen using a multi-stage stratified clustering sample method and represent $1 \%$ of the population. Household questionnaires and individual questionnaires collected information on behavioral risk factors and self-reported chronic disease. Anthropometric measurements, blood pressure measurements, and blood tests were also included. In 2004, the Kadoorie Study of Chronic Disease in China (KSCDC) was launched..$^{50,51}$ It is a nationwide, prospective cohort study involving 10 diverse localities (five rural counties and five urban districts). The KSCDC is an open-ended prospective study with broad research aims. Data were collected by faceto-face interviews and physical examinations. Both plasma and buffy coat samples were collected and stored. KSCDC recruited $\sim 500,000$ adults initially aged 35-74 years from the general population across China from 2004 to $2009 .^{52}$ The KSCDC is the largest blood-based prospective study ever conducted in the world. It was carefully designed with a range of comprehensive computerized systems for reliable and efficient data collection and management. China also participated in the Prospective Urban Rural Epidemiological 
(PURE) study, ${ }^{53}$ which enrolled individuals aged $35-70$ years from 17 countries to examine primary risk factors for obesity, hypertension, dysglycemia dyslipidemia, and cardiovascular diseases. In China, 115 (45 urban and 70 rural) communities from 12 provinces participated, and 46,285 persons were recruited from 2005 to $2009 .{ }^{54}$ Participants were followed for incident cardiovascular disease and death for 10 years.

The China National Stroke Registry was launched in 2007 to recruit patients with diagnoses of acute stroke events from 132 hospitals ( $1 \%$ of the general hospitals) that cover all 31 administrative regions at the provincial level and Hong Kong. ${ }^{55,56}$ The primary objectives of the registry were to evaluate the quality of care during acute hospitalizations and consequences of the acute events, including recurrence of events, mortality, and disability. ${ }^{55}$ In total, 22,451 patients were recruited and followed through phone interviews up to 24 months after disease onset.

\section{Medical birth registers}

A nationwide medical birth register has not been set up in China. In 1994, the law on Maternal and Infant Care was promulgated. According to the law, a medical certificate of birth has to be issued and include information on gestational age, birth weight, birth height, and health status at time of birth. ${ }^{57}$ Most hospitals hold medical records of birth delivery either as paper forms or electronic forms even before 1994. However, the medical birth data existed as "information silos" before being integrated in the health care data after the health care reform.

The birth defects surveillance in China started in Chengdu in 1982 and Beijing, Gansu, Anhui, Liaoning, and Jiangxi in $1983 .^{58}$ The Chinese Ministry of Health launched the "perinatal birth defects surveillance and etiology of high-risk and high-incidence birth defects" in 1986, which covered over 1.2 million perinatal births in 945 hospitals across 29 provinces, autonomous regions, and municipalities. In 1988, the Chinese Birth Defects Monitoring Network was established and was updated by a new electronic, web-based reporting system in 2006. The Shanghai birth cohort is a preconception and pregnancy cohort, which recruits couples who plan to become pregnant and pregnant women $<16$ gestational weeks with the aim of studying the effects of genetic, environmental, and behavioral factors on reproductive health, pregnancy outcomes, child growth, development, and risks of diseases. The cohort began to recruit participants in 2013. Children are followed up to 24 months after birth. The cohort may become a trigger for establishing a national birth cohort. ${ }^{59}$

\section{Death registers}

A nationwide death registration has not been set up. Vital registration is mainly based on the DSP system, which is used primarily for surveillance of communicable diseases. ${ }^{34}$ In the DSP, family members report the death to the registration office of the nearest township hospital to get a death certificate. Staff in the registration office fills in the death certificate based on information from family members and available medical records or documents. They send a copy to the county $\mathrm{CDC}$ where the cause of death is registered using codes from the International Classification of Diseases, 9th edition. ${ }^{60}$ Surveillance on death from the system provides population level data on causes of death on an annual basis. ${ }^{60}$ There are other sources of mortality data such as the census and annual surveys of changes in the population, and largescale retrospective household surveys. ${ }^{60}$

\section{China liver transplant registry}

The China Liver Transplant Registry was set up in 2005 and was registered as the first nationwide liver transplant registry by the Ministry of Health in $2008 .{ }^{61}$ It includes data from 80 liver transplant centers and requires that each center reports information about liver donor and recipient and surgical information within 24 hours after transplantation. Each center has designated personnel in charge of the data input. The registry data are also open for scientific researchers in each center. The registry can help to follow up patients and improve cooperation among liver transplant centers. In 2010, it was the third largest liver transplant registry in the world. ${ }^{61}$

\section{Discussion}

China is undergoing a complex health care reform covering a population of 1.37 billion people. The complex health care reform and the achievements of universal health insurance coverage lead to both opportunities and challenges in health research, including clinical epidemiology research.

\section{Opportunities}

China is a large country with a large population. The population in a municipality or province can be equal to or larger than the population in a medium or small country. Building up a nationwide register system is challenging, but provides many opportunities. Completion of province-based, municipality-based, even county-based registers is useful and important steps toward the final goal of a nationwide, unified health care register. The establishment of an electronic medical record system and the universal health insurance coverage are important steps in the process, which will expand Chinese health research in a broad perspective. Application of the "Resident Health Card" in the health care will not only make administration convenient, but also is a key link of life-course health data, which will add a deeper perspective to Chinese 
health research. ${ }^{12}$ Personal ID numbers are now increasingly used in daily life of Chinese citizens, for example, in phone registers, when buying train or plane ticket, and for registration at hotels. Potential linkage of health data with other types of data such as pollution, cell phone exposure, and accidents may provide unique research opportunities when the data are open for sharing. The existing registers and research projects and health data from the health care reform may benefit each other. Information from existing registers and research projects can provide data that health service data do not contain, while health service and health insurance data may extend the follow-up of the participants in existing projects. The KSCDC cohort, for example, was set up in $2004 .{ }^{51}$ In a recently published study, the authors have already been able to collect "information about major diseases and hospitalization through linkages with disease registries and national health insurance claims databases". ${ }^{2}$

Reforming complex health care systems can be a neverending process, but it is never too late to pay more attention to epidemiological research, which in turn can provide evidence based guidance to the reform. Health data in the process of the reform may also provide valuable information for research. In the future, China will have demand for more researchers and data managers in epidemiology, including clinical epidemiology, to explore the huge data sources. More cooperation between researchers within China, Chinese researchers living abroad, and other international researchers is anticipated. More large-scale projects will be established on a national or an international basis, and Chinese health care data will contribute more to health research worldwide.

\section{Challenges}

It is a challenge to maintain health insurance schemes, since it requires adequate funding, competent medical staff, and sufficient equipment. However, these challenges are beyond the scope of this review. Instead we will discuss challenges in the perspective of scientific research.

\section{Integration of different health care insurance schemes}

There is unequal distribution of health care resources, including differences in the competences of clinical and professional personnel working in urban and rural areas, and in the quality of large hospitals and basic health care institutions. This is despite the fact that China has now achieved universal health insurance coverage. The insurance policies, including the insurance premium and reimbursement coverage, are different to the various target populations. ${ }^{11}$ Unequal development in the insurance schemes is still a real threat to the objective of providing equal health care for all. ${ }^{11}$ For example, the benefit packages of elderly participants in the UEBMI are significantly better than those of the URBMI and the NCMS and the total health care expenditures of elderly participants in the UEBMI are markedly higher than those of the elderly in the other two insurance schemes. ${ }^{11}$ Different insurance policies may influence the choice of health care facilities at different levels, among which diagnosis validity and health care quality varies. This may introduce selection bias in observational epidemiology research.

\section{Quality of care and health care efficiency}

Increase in insurance coverage and a better insurance profile do not ensure better access to health care services. The study based on the three Chinese National Health Surveys indicated that the increase in insurance coverage and reimbursement proportion was associated with increased use of health care services including hospital admissions, hospital delivery, and antenatal care. However, the average length of stay in hospital and the rate of cesarean sections exceeded the clinical needs. ${ }^{13}$ It is suggested that quality of care and efficiency should be closely monitored. ${ }^{13} \mathrm{~A}$ recent cross-sectional study in Shanghai indicated that hypertension patients enrolled in the NCMS or the URBMI were more likely to control their blood pressure than patients enrolled in the UEBMI. ${ }^{63}$ A possible explanation may be that the UEBMI covered expenditures in pharmacies and provided more convenient access to antihypertensive drugs, whereas patients enrolled in the URBMI or the NCMS had to go to community health service centers or general hospitals for their antihypertensive drugs. Thus, patients with UEBMI insurance may get less professional medical advice on individual-based management of hypertension if they got antihypertensive drugs from a pharmacy. ${ }^{63}$

\section{Sharing of data}

Though HIT and hospital information network is improving, nationwide data sharing is still far away. The three insurance schemes are managed by two different administrative organizations. The Chinese Government has started to integrate the health insurance schemes, but data sharing between the two systems has not been fully discussed and solved. Repetitions exist in the two health insurance systems. A better link between basic medical insurance, critical illness insurance, and the MA program is also necessary for unifying the insurance system. Although many hospitals have set up their own electronic health record system, the systems may vary significantly between hospitals and are usually not integrated or interoperable. ${ }^{16}$ Once health data are available for researchers, relevant rules or regulations are necessary to ensure data security and availability. 


\section{Standardization of registries}

Due to its size, China shows diversity both on disease profiles and socioeconomic development. Although guidelines on data collection in registries exist, data quality varies, for example in the cancer registry. ${ }^{40}$ Researchers who have used the health insurance data indicated a lack of standardized, reliable, and systematic coding of diagnoses and prescriptions. ${ }^{64}$ China's health care quality management and control systems need further improvement. ${ }^{12}$ Data accuracy and data integrity should take into consideration in implementation of health care data register. Another issue is the outpatient data. In China, it is required that medical records regarding hospitalization are kept by the medical institutions. However, outpatient medical records, including emergency medical records, have not been paid much attention. Even in official documents it states that outpatient records and emergency care records are to be kept by patients unless the medical institutions have established a system to keep them. ${ }^{29}$

\section{Socioeconomic inequality}

Unlike some western countries, Chinese patients usually do not have a regular physician like a general practitioner. The three-tier referral system in the rural area is not the same as the referral system in western countries. Individuals in China can decide where to resort for health care based on their residence, economic condition, and knowledge. This occurs still more often due to better affordability of care after the introduction of universal insurance coverage, ${ }^{65}$ which may lead to socioeconomic inequality in health care even within the same insurance program. ${ }^{66} \mathrm{~A}$ study indicated that in the NRCMS, the pro-rich inequality dominated the inpatient care ${ }^{66}$ On the other hand, people in the poorest areas cannot even afford small health care expenses after reimbursement from health care insurance. The same concern exists for vulnerable groups in urban areas. ${ }^{11}$ Even for those who can afford health care, loss to follow-up is quite likely due to lack of continuity of coordinated care. Although the MA program helps the poor, different use of health care services due to socioeconomic inequality should not be ignored.

\section{Data storage, data safety, and ethical issues}

With the universal coverage of health insurance and construction of electronic health records in many Chinese hospitals, data storage and safety is a real challenge. Much attention should be paid to the ethical issues that might arise. ${ }^{67}$ Security breaches threaten patient privacy when confidential health information is made available to others without the consent of the individual. ${ }^{67}$ Strict privacy and security policies, supportive technology, and routine random audits are possible solutions. ${ }^{67}$ The Nordic countries have achieved success with epidemiological research based on population-based registries, to a large extent due to public trust in research. ${ }^{68}$ In these countries, health care data are usually stored in a statistical center and researchers can access data remotely. However, researchers have to obey the data protection regulations. Any potential way to identify an individual is forbidden.

\section{Conclusion}

China has successfully achieved universal health insurance coverage by implementing three health care insurance schemes. The Chinese Government has made efforts to build up health information including electronic medical records. The establishment of the universal health care insurance and health information provides a huge opportunity for clinical epidemiology research. However, China is also facing challenges to maintain and complete the complex health care reform. To speed up the process in an efficient way, China may learn from other countries and strengthen international cooperation.

\section{Acknowledgments}

We thank Ziliang Wang from Fudan University for her assistant in searching the literature in Chinese on the Chinese register systems.

Dr. Yuelian Sun is supported by the European Commission Directorate-General for Health and Food Safety on European Study on the Burden and Care of Epilepsy (ESBACE) project.

\section{Disclosure}

The authors report no conflicts of interest in this work.

\section{References}

1. Blumenthal D, Hsiao W. Lessons from the East-China's rapidly evolving health care system. $N$ Engl J Med. 2015;372(14):1281-1285.

2. Yu H. Universal health insurance coverage for 1.3 billion people: what accounts for China's success? Health Policy. 2015;119(9):1145-1152.

3. China Statistical Yearbook-2015. Beijing China Statistics Press; 2015.

4. Liu H, Rizzo JA, Fang H. Urban-rural disparities in child nutrition-related health outcomes in China: the role of hukou policy. BMC Public Health. 2015;15:1159.

5. Goodkind D, West LA. China's floating population: definitions, data and recent findings. Urban Studies. 2002;39(12):2237-2250.

6. China Human Development Report 2013. Sustainable and Liveable Cities: Toward Ecological Urbanisation. Beijing: United Nations Development Program; 2013. Available from http://www.cn.undp.org/content/ dam/china/docs/Publications/UNDP-CH_2013\%20NHDR_EN.pdf. Accessed December 5, 2016.

7. chinadaily.com.cn. Summary of China's Migrant Population Report for 2013. Available from http://en.nhfpc.gov.cn/2014-05/16/c_46667.htm. Accessed December 5, 2016.

8. Brown RE, Píriz DG, Liu Y, Moore J. Reforming health care in China-historical, economic and comparative perspectives. Ford School of Public Policy Sites; 2012. Available from: http://sites.fordschool. umich.edu/china-policy/files/2012/07/PP_716_Final_Policy_Paper_ Health-Final.pdf. Accessed December 5, 2016. 
9. Dong H, Duan S, Bogg L, et al. The impact of expanded health system reform on governmental contributions and individual copayments in the new Chinese rural cooperative medical system. Int J Health Plann Manage. 2016;31(1):36-48.

10. Liang L, Langenbrunner JC. The long march to universal coverage: lessons from China. Universal Health Coverage Studies Series (UNICO); studies series; no. 9. Washington DC : World Bank. 2013.

11. Liu X, Wong H, Liu K. Outcome-based health equity across different social health insurance schemes for the elderly in China. BMC Health Serv Res. 2016;16:9.

12. Cheng TM. Early results of China's historic health reforms: the view from minister Chen Zhu. Interview by Tsung-Mei Cheng. Health Aff (Millwood). 2012;31(11):2536-2544.

13. Meng Q, Xu L, Zhang Y, et al. Trends in access to health services and financial protection in China between 2003 and 2011: a cross-sectional study. Lancet. 2012;379(9818):805-814.

14. Xi B, Zhou C, Zhang M, Wang Y, Xu L. Maternal and child mortality in China. Lancet. 2014;383(9921):953-954.

15. Shi L. Health care in China: a rural-urban comparison after the socioeconomic reforms. Bull World Health Organ. 1993;71(6):723-736.

16. Fang H. The Chinese health care system, 2015. In: Mossialos E, Wenzl M, Osborn R, Sarnak D, editors. 2015 International Profiles of Health Care Systems, 2015. Commonwealth Fund; 2016.

17. Barber SL, Yao L. Health insurance systems in China: a briefing note World Health Organization; 2010. Available from: http://www.who.int/ healthsystems/topics/financing/healthreport/37ChinaB_YFINAL.pdf. Accessed December 5, 2017.

18. Meng QTS. Universal coverage of health care in China: challenges and opportunities. Procedia Soc Behav Sci, 2010;77(2013):330-340.

19. Yip WC-M, Hsiao WC, Chen W, Hu S, Ma J, Maynard A. Early appraisal of China's huge and complex health-care reforms. The Lancet. 2012;379:833-842.

20. Ministry of Human Resources and Social Development. [Notice on the Urban Residence Basic Medical Insurance in 2016]. Available from: http://www.mohrss.gov.cn/SYrlzyhshbzb/shehuibaozhang/zcwj/ yiliao/201605/t20160506_239541.html. Accessed December 5, 2016. Chinese.

21. The General Office of the State Council of China [Notice of the General Office of the State Council on Issuing the 2014 Wrap-up Report and 2015 Major Task List on Deepening the Medical and Health Care System Reform]. Available from: http://www.mof.gov.cn/zhengwuxinxi/ zhengcefabu/201505/t20150511_1229616.htm. Accessed December 5, 2016. Chinese.

22. Huang X, Pelissier A, Audibert M, Mathonnat J. The impact of the new rural cooperative medical scheme on activities and financing of township hospitals in Weifang, China. Availalbe from: http://cerdi.org/uploads/ sfCmsContent/html/333/PelissierHuang.pdf. Accessed December 5, 2016.

23. The General Office of the State Council of China. [Opinions of the General Office of the State Council on Comprehensively Implementing Critical Illness Insurance for Urban and Rural Residents]. 2015. Available from: http://www.mohrss.gov.cn/SYrlzyhshbzb/shehuibaozhang/ zcwj/yiliao/201508/t20150804_216852.html. Acccessed December 5, 2016. Chinese.

24. Liu P, Jiang L, Li C, Sun M, Rieger A, Hao M. How to deal with burden of critical illness: a comparison of strategies in different areas of China. Pak J Med Sci. 2014;30(3):659-663.

25. China's critical illness insurance benefits 1 million patients. Xinhua News. 2015 February 6; Section China. Available from: http://www. china.org.cn/china/2015-02/06/content_34757261.htm. Accessed December 5, 2016.

26. The General Office of the State Council of China [Guiding Opinions of the General Office of the State Council on Establishing the Disease Emergency Rescue System]. 2013. Available from: http://www.gov.cn/ zwgk/2013-03/01/content_2342656.htm. Accessed December 5, 2016. Chinese.
27. The General Office of the State Council of China. Opinions of the State Council on Integrating the Basic Medical Insurance Systems for Urban and Rural Residents. 2016. Available from: http://www. mohrss.gov.cn/SYrlzyhshbzb/shehuibaozhang/zcwj/yiliao/201601/ t20160112_231624.html. Accessed December 5, 2015.

28. Lei J, Sockolow P, Guan P, Meng Q, Zhang J. A comparison of electronic health records at two major Peking University Hospitals in China to United States meaningful use objectives. BMC Med Inform Decis Mak. 2013;13:96.

29. The National Health and Family Planning Commission. [database on the Internet] Regulation on medical records management in medical institutions; 2013. Available from: http://english.gov.cn/policies/latest_releases/2014/08/23/content_281474983027052.htm. Accessed December 5, 2016

30. Zhang L, Chen Y, Yue L, et al. Medication use patterns, health care resource utilization, and economic burden for patients with major depressive disorder in Beijing, People's Republic of China. Neuropsychiatr Dis Treat. 2016;12:941-949.

31. Sun L, Zou LX, Han YC, et al. Forecast of the incidence, prevalence and burden of end-stage renal disease in Nanjing, China to the Year 2025. BMC Nephrol. 2016;17(1):60.

32. Han YC, Huang HM, Sun L, et al. Epidemiological study of RRT-treated ESRD in Nanjing - a ten-year experience in nearly three million insurance covered population. PLoS One. 2016;11(2):e0149038.

33. Wang LD, Wang Y, Yang GH, Ma JQ, Wang LP, Qi XP. China information system for disease control and prevention (CISDCP). The National Bureau of Asian Research. Available from http://www.pacifichealthsum mit.org/downloads/HITCaseStudies/Functional/CISDCP.pdf. Accessed January 26, 2013.

34. Chinese Center for Disease Control and Prevention (CCDC). China Chronic Disease and Risk Factor Surveillance; 2010. Available from: http://ghdx.healthdata.org/record/china-chronic-disease-and-riskfactor-surveillance-2010. Accessed December 5, 2016.

35. Chen X, Chen C, Zhang Y, Yuan R, Ye J. The effect of health insurance reform on the number of cataract surgeries in Chongqing, China. BMC Health Serv Res. 2011;11:67.

36. Yan WR, Nie SF, Xu B, Dong HJ, Palm L, Diwan VK. Establishing a web-based integrated surveillance system for early detection of infectious disease epidemic in rural China: a field experimental study. $B M C$ Med Inform Decis Mak. 2012;12:4.

37. Yang W, Li Z, Lan Y, et al. A nationwide web-based automated system for outbreak early detection and rapid response in China. Western Pac Surveill Response J. 2011;2(1):10-15.

38. Chen JG, Zhu J, Parkin DM, et al. Trends in the incidence of cancer in Qidong, China, 1978-2002. Int J Cancer. 2006;119(6):1447-1454.

39. Yang L, Parkin DM, Whelan S, et al. Statistics on cancer in China: cancer registration in 2002. Eur J Cancer Prev. 2005;14(4):329-335.

40. Chen W, Zheng R, Baade PD, et al. Cancer statistics in China, 2015. CA Cancer J Clin. 2015;66(2):115-132.

41. Wei KR, Chen WQ, Zhang SW, Liang ZH, Zheng RS, Ou ZX. Cancer registration in the Peoples Republic of China. Asian Pac J Cancer Prev. 2012;13(8):4209-4214.

42. Yuan JM. The Shanghai cohort study. Bethesda, MD: National Cancer Insitute. Available from: https://epi.grants.cancer.gov/Consortia/members/shanghai.html. Accessed December 5, 2016.

43. Yuan JM, Ross RK, Wang XL, Gao YT, Henderson BE, Yu MC. Morbidity and mortality in relation to cigarette smoking in Shanghai, China. A prospective male cohort study. JAMA. 1996;275(21):1646-1650.

44. Ross RK, Yuan JM, Yu MC, et al. Urinary aflatoxin biomarkers and risk of hepatocellular carcinoma. Lancet. 1992;339(8799):943-946.

45. London SJ, Yuan JM, Chung FL, et al. Isothiocyanates, glutathione S-transferase M1 and T1 polymorphisms, and lung-cancer risk: a prospective study of men in Shanghai, China. Lancet. 2000;356(9231):724-729.

46. Luu HN, Blot WJ, Xiang YB, et al. Prospective evaluation of the association of nut/peanut consumption with total and cause-specific mortality. JAMA Intern Med. 2015;175(5):755-766. 
47. Zheng W, Chow WH, Yang G, et al. The Shanghai women's health study: rationale, study design, and baseline characteristics. Am J Epidemiol. 2005;162(11):1123-1131.

48. Shu XO, Li H, Yang G, et al. Cohort profile: the Shanghai men's health study. Int J Epidemiol. 2015;44(3):810-818.

49. Cai H, Zheng W, Xiang YB, et al. Dietary patterns and their correlates among middle-aged and elderly Chinese men: a report from the Shanghai Men's Health Study. Br J Nutr. 2007;98(5):1006-1013.

50. Chen Z, Chen J, Collins R, et al; China Kadoorie Biobank (CKB) collaborative group. China Kadoorie Biobank of 0.5 million people: survey methods, baseline characteristics and long-term follow-up. Int J Epidemiol. 2011;40(6):1652-1666.

51. Chen Z, Lee L, Chen J, et al. Cohort profile: the Kadoorie study of chronic disease in China (KSCDC). Int J Epidemiol. 2005;34(6): 1243-1249.

52. Lewington S, Lacey B, Clarke R, et al. The Burden of Hypertension and Associated Risk for Cardiovascular Mortality in China. JAMA Intern Med. 2016;176(4):524-532.

53. Li Y, Zhou L, Coulter D, et al. Prospective cohort study of the association between use of low-dose oral contraceptives and stroke in Chinese women. Pharmacoepidemiol Drug Saf. 2006;15(10):726-734.

54. Li W, Gu H, Teo KK, et al; PURE China Investigators. Hypertension prevalence, awareness, treatment, and control in 115 rural and urban communities involving 47000 people from China. J Hypertens. 2016;34(1):39-46.

55. Wang Y, Cui L, Ji X, et al. The China National Stroke Registry for patients with acute cerebrovascular events: design, rationale, and baseline patient characteristics. Int J Stroke. 2011;6(4):355-361.

56. Li Q, Hsia J, Yang G. Prevalence of smoking in China in 2010. N Engl $J$ Med. 2011;364(25):2469-2470.

57. Li S, Zhang Y, Feldman MW. Birth registration in China: practices, problems and policies. Popul Res Policy Rev. 2010;29(3):297-317.
58. Dai L, Zhu J, Liang J, Wang YP, Wang H, Mao M. Birth defects surveillance in China. World J Pediatr. 2011;7(4):302-310.

59. Zhang J, Tian Y, Wang W, Huang H, Shen X, Sun K. Toward a national birth cohort study in China. Am J Public Health. 2016;106(12):2111-2112.

60. Yang G, Hu J, Rao KQ, Ma J, Rao C, Lopez AD. Mortality registration and surveillance in China: history, current situation and challenges. Popul Health Metr. 2005;3(1):3.

61. Liu Y, Lu S. Clinical Value of China Liver Transplant Registry. Chinese Medical Record. 2010;11:2.

62. Du H, Li L, Bennett D, et al; China Kadoorie Biobank Study. Fresh fruit consumption and major cardiovascular disease in China. $N$ Engl J Med. 2016;374(14):1332-1343.

63. Zhang X, Zhang Y, Xiao X, Ma X, He J. The relation between health insurance and management of hypertension in Shanghai, China: a cross-sectional study. BMC Public Health. 2016;16:959.

64. Huang Y, Vemer P, Zhu J, Postma MJ, Chen W. Economic burden in Chinese patients with diabetes mellitus using electronic insurance claims data. PLoS One. 2016;11(8):e0159297.

65. Wu D, Lam TP. Underuse of primary care in China: the scale, causes, and solutions. J Am Board Fam Med. 2016;29(2):240-247.

66. Yuan S, Rehnberg C, Sun X, Liu X, Meng Q. Income related inequalities in New cooperative medical scheme: a five-year empirical study of Junan County in China. Int J Equity Health. 2014;13:38.

67. Ozair FF, Jamshed N, Sharma A, Aggarwal P. Ethical issues in electronic health records: a general overview. Perspect Clin Res. 2015;6(2): $73-76$.

68. Ludvigsson JF, Haberg SE, Knudsen GP, et al. Ethical aspects of registrybased research in the Nordic countries. Clin Epidemiol. 2015;7:491-508.

69. Shebao.southmoney.com. [The proportion of medical insurance reimbursement for urban workers in 2014]. Available from http:// shebao.southmoney.com/yiliao/baoxiao/201402/29656.html. Accessed February 22, 2017. Chinese.
Clinical Epidemiology

\section{Publish your work in this journal}

Clinical Epidemiology is an international, peer-reviewed, open access, online journal focusing on disease and drug epidemiology, identification of risk factors and screening procedures to develop optimal preventative initiatives and programs. Specific topics include: diagnosis, prognosis, treatment, screening, prevention, risk factor modification,

Submit your manuscript here: https://www.dovepress.com/clinical-epidemiology-journa

\section{Dovepress}

systematic reviews, risk and safety of medical interventions, epidemiology and biostatistical methods, and evaluation of guidelines, translationa medicine, health policies and economic evaluations. The manuscrip management system is completely online and includes a very quick and fair peer-review system, which is all easy to use. 